IZA DP No. 8567

Climate Vulnerability, Communities' Resilience and Child Labour

Delphine Boutin

October 2014 


\title{
Climate Vulnerability, Communities' Resilience and Child Labour
}

\author{
Delphine Boutin \\ CERDI, University of Auvergne \\ and IZA
}

\section{Discussion Paper No. 8567 \\ October 2014}

\author{
IZA \\ P.O. Box 7240 \\ 53072 Bonn \\ Germany \\ Phone: +49-228-3894-0 \\ Fax: +49-228-3894-180 \\ E-mail: iza@iza.org
}

Any opinions expressed here are those of the author(s) and not those of IZA. Research published in this series may include views on policy, but the institute itself takes no institutional policy positions. The IZA research network is committed to the IZA Guiding Principles of Research Integrity.

The Institute for the Study of Labor (IZA) in Bonn is a local and virtual international research center and a place of communication between science, politics and business. IZA is an independent nonprofit organization supported by Deutsche Post Foundation. The center is associated with the University of Bonn and offers a stimulating research environment through its international network, workshops and conferences, data service, project support, research visits and doctoral program. IZA engages in (i) original and internationally competitive research in all fields of labor economics, (ii) development of policy concepts, and (iii) dissemination of research results and concepts to the interested public.

IZA Discussion Papers often represent preliminary work and are circulated to encourage discussion. Citation of such a paper should account for its provisional character. A revised version may be available directly from the author. 
IZA Discussion Paper No. 8567

October 2014

\section{ABSTRACT}

\section{Climate Vulnerability, Communities' Resilience and Child Labour ${ }^{*}$}

This article clarifies and quantifies the causal impact of climate change vulnerability on child labour incidence and intensity. For this purpose, we create an index of vulnerability to climate change, composed of biophysical vulnerability and communities' resilience. Both, participation to economic activities and to household chores have been taken into account. We find that climate vulnerability negatively affects child labour incidence and intensity, while has no significant impact on household chores. We conclude that child labour is an adjustment variable to local labour market conditions, not correlated with communities' resilience.

JEL Classification: J22, J43, 055, Q54

Keywords: $\quad$ climate change, Malawi, child labour, vulnerability

Corresponding author:

Delphine Boutin

CERDI

65 Boulevard F. Mitterrand

Boite Postale 320

63009 Clermont-Ferrand CEDEX 1

France

E-mail: delphine.boutin@udamail.fr 


\section{Introduction}

While Sub-Saharan Africa accounts for only two per cent of global carbon dioxide emissions, this region is expected to suffer a disproportionately large share of the negative impacts of global climate change. African people are particularly vulnerable to climate change. Along with greater exposure to climatic risks, Sub-Saharan people are also characterized by limited resilience capacities. In many of African societies, the use of human resources, through for example child labour, has already been an informal livelihood and insurance strategy for generations as response to shocks. Children play an important economic role in Sub-Saharan Africa: according to the last ILO estimates, one child out of three is economically active. We aim to clarify and quantify the relationships between climate change and child labour. Numerous papers have analysed the links between shocks, household vulnerability and child labour (Grootaert et Kanbur [1995]; Guarcello et al. [2010]). However, to the best of our knowledge, this is the first paper that attempts to specifically study the impacts of climate changes on the children's economic status. ${ }^{1}$

Our main hypothesis is that child labour is used by households as a climate risks management strategy. There are different reasons for which climate change may impact child labour. First, climate change is expected to affect children belonging to farm households. The experience of a severe climate event - droughts, flooding - causes a sudden and unanticipated drop in the household earnings. According to the luxury axiom (Basu and Van [1998]), the reduction in the household income should increase child labour. By performing economic activities, a child directly or indirectly contributes to household income. Thus, households may resort to child labour in order to cope with the damages done. Second, climate change is also expected to affect children's status through the modification of the local labour market conditions. In rural areas, repeated exposure to negative climate events may reduce the farm labour demand, and as a consequence the child labour demand because the majority of rural child labourers works for their family farm. Third, climate change can also be seen as a gradual process. The repetition of extreme climate events exacerbates the risk perception and increases the necessity to find new adaptation behaviours. By diversifying risks, child work help smooth transitory income shocks and is a mechanism providing for security against future risks.

It is an empirical question to determine which of these antagonist effects prevail. Our analysis focuses on Malawi, an interesting case of study concerning interactions between climate change and child labour. The climate in Malawi is naturally variable, in large measure due to its topography. Both temperatures and rainfall vary considerably, depending on alti-

\footnotetext{
${ }^{1}$ Some reports (Understanding children's work programme, [2011]; Unicef, [2008]) have highlighted the potential links between the two phenomena, but these studies intend to inform and warn a large audience, without providing rigorous analytical analysis.
} 
tude and the multitude of terrains. This variety of micro-climates is likely to lead to different levels of climatic vulnerability, according to the household place of residence. Second, the incidence of child labour in Malawi is high: nearly one quarter of the 7-14 years old children is economically active and the same proportion perform domestic tasks. This finding presupposes that children are part of the household subsistence strategies, at least in rural areas. In the meantime, school attendance rate is high (around 90\%). Consequently, we assume that in Malawi the climate change would have no impact on school attendance, ${ }^{2}$ or in others words that decisions regarding school attendance and children's work are not taken simultaneously. Thus we can focus on the specific impact of climate change on child labour incidence and intensity.

The paper is organized as follows: the second section reviews how to measure climate vulnerability. A detailed explanation of the methodology used is provided in the third part, while the fourth section gauges and analyses the climate change vulnerability impact on children's work. The last section concludes.

\section{Using child labour to cope with climate vulnerability}

Using child labour as a response to climate change has not been adequately thought through by the economic literature, despite the fact that this issue has been recently mentioned in two institutional reports (Unicef [2008], UCW, [2011]), and that links between parental vulnerability and child labour no longer need to be demonstrated (Boutin, [2012a]). We briefly review in this section the expected impacts of climate change on child labour.

Repeated exposure to climate shocks can alter the household standard of living. Child labour is often used to generate an additional income (monetary or not) in order to compensate losses due to the climate shock experienced. The child contribution to household income may enable households to pay some expenses, especially for poor households having limited access to credit and little saving capacities. Previous literature highlights that the probability of a child participating to economic activities increases when a household suffers from a shock (Beegle et al., [2003], Guarcello et al., [2010]; Bohara and Vasquez, [2010]) ${ }^{3}$.

If empirical studies converge to the same conclusion, in theory, the impacts of shocks on child labour is ambiguous. For example, parents may prefer save some money by eliminating

\footnotetext{
${ }^{2}$ This hypothesis has been tested using the different model specifications presented in the next sections.

${ }^{3}$ Beegle et al. [2003] show that child labour is used to respond to transitory income shocks in Tanzania, when households have no access to credit. Guarcello et al. [2010] analyse the impact of different shocks on school and work participation decisions. They conclude to a positive relationship between shocks and child labour. Bohara and Vasquez [2010] find that poor households tend to use child labour to cope with socio-economic shocks and natural disasters in Guatemala.
} 
or reducing some expenses (by consuming less, or by retiring children from school) with the aim of not increasing children's participation to economic activities. The impact of shocks on child labour can even be negative: a risk-adverse household may choose to enrol their children to school in order to secure futures incomes. In the same vein, the increase in frequency of climate disasters may also lead to a reduction in the total volume of economic activities, especially in rural areas. In a country where rain-fed agriculture is dominant, repeated extreme floods and droughts can destroy fields and farm unit, and consequently reduce the rural labour demand. In this context, child labour should decrease, as children participation to work is an adjustment variable in the labour market. To the best of our knowledge, no study has demonstrated that a reduction in the volume activity reduce the child labour demand. However, there is no lack of empirical evidence on the inverse, that is to say, on the effect of increases in local labour demand on young children's labour supply in developing countries. Parikh and Sadoulet [2005] for example find a positive association between local area employment and work using a cross sectional of Brazilian (PNAD) data. Similar results are found by Guarcello et al. [2006] for Ethiopia and Manacorda and Kondylis [2006] for Tanzania. In a recent paper on Brazil that uses the same data as the ones used in this study, Krueger [2007] uses the variation in the value of coffee production across Brazilian counties and time to measure changes in local economic conditions. She shows that an increase in the value of coffee production induces a fall in school attendance and a rise in child labour among children of parents with low and intermediate levels of education.

Although climate change is expected to increase the intensity and frequency of climate shocks, it is a medium and long-term process. As a consequence, households need to change their behaviour and strategies in order to adapt to the climate change consequences and to increase their resilience to future climate shocks. Ex-ante risks management strategies, including the diversification of economic activities ${ }^{4}$, aims at reducing futures risks associated with income. Not "putting all your eggs in one basket" is a strategy often used, requiring the use of a large workforce to manage and maintain the household economic activities. In the absence of perfect land, labour and credit market, households show a clear preference for their own children. Indeed, children are an easy and cheap way to face market failures, and incentives to hire their own children are numerous (Boutin [2012b]; Dumas [2013]) ${ }^{5}$.

For determining which of these effects prevails in Malawi, we should keep in mind that

\footnotetext{
${ }^{4}$ In addition to pluri-activity, migration, sale of assets, informal credit and insurance systems are strategies often used by African households to adapt with climate change.

${ }^{5}$ Work in farms is seasonal and geographically concentrated. Households may regularly be confronted by a lack of labour supply. It is easier for poor households to engage their own children, a workforce still at their disposal. Even for richer households, moral hazard concerns may induce a preference for the familial workforce. In fact children are often considered as easier to manipulate, to supervise and less likely to commit thefts.
} 
the impacts of climate change on child labour depend if the household is able to cope with the worsening of the climatic conditions or to smooth consumption during temporary shocks.

\section{Measuring the vulnerability to climate change in the Malaw- ian context}

\subsection{Conceptual framework}

In recent climate research, attention has been paid to the concept of vulnerability. ${ }^{6}$ Despite the abundance of studies on climate change vulnerability, no standard definition exists. Given the variety of approaches, it is worth being explicit about the conceptual framework. Following the Intergovernmental Panel on Climate Change (IPCC), we define the vulnerability to climate change as "the degree to which geophysical, biological and socio-economic systems are susceptible to, and unable to cope with, adverse impacts of climate change" (Fussel [2007]).

Figure 1: Conceptual framework to study the vulnerability to climate change impacts on child labour.

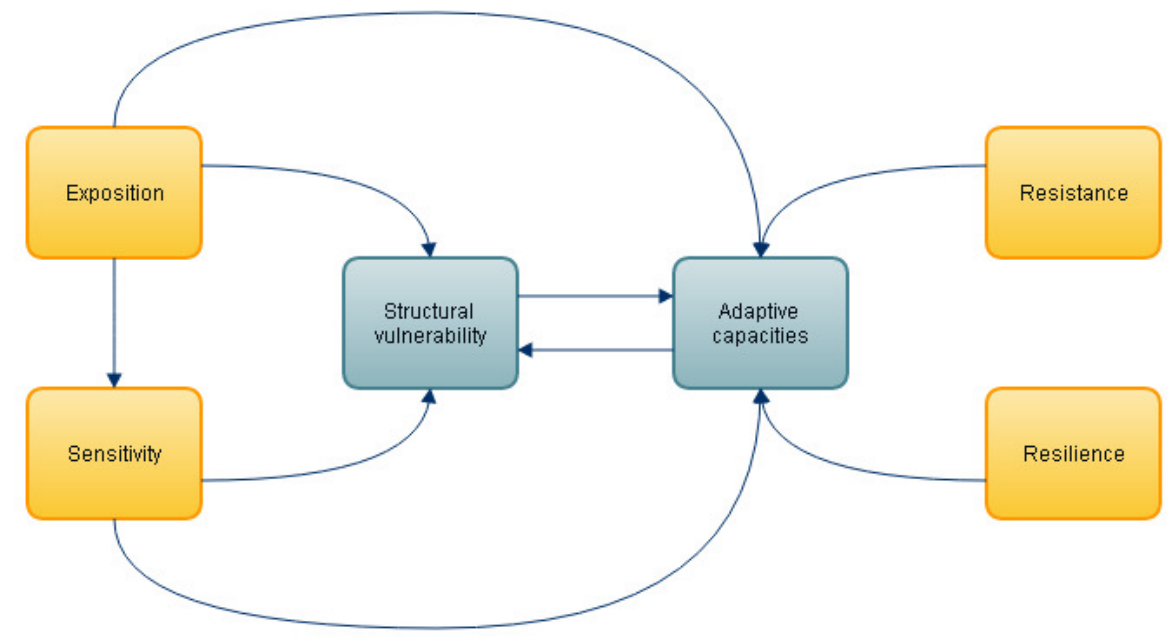

Source: Third Integrated Household Survey, Malawi, 2010-2011

In this paper, an impact is a function of hazard exposure and of both the biophysical vulnerability and the social resilience. Biophysical vulnerability (resp. social resilience) is defined as the sensitivity of the natural (resp. human) environment to exposure. Whether

\footnotetext{
${ }^{6}$ See for example Adger [1999], Fussel [2007], Guillaumont and Simonet [2011].
} 
an exposure translates into a hazard depends on the nature of the vulnerability: if the natural environment is particularly sensitive and the human population have little resilience capacities, then the impact will be high. However, if the resilience is higher due to a more appropriate coping capacity, then exposure of the same nature may result in a smaller or even no impact.

\subsection{Biophysical vulnerability and communities' resilience.}

Evaluating the vulnerability to climate change is challenging as the effects of climatic variation have just been felt or experienced. Self-reported information, as droughts and flooding experienced by households during the reference year, is contaminated by individual errors and variation in perception, and thus may bias the results. One may suspect that omitted variables (and measurement errors) affect both the control variables and the child labour status. Moreover, unobserved heterogeneity may in general make climate shocks variables endogenous. This is the case, for example, when people have a general negative attitude regarding the adoption of new technologies. They are more likely to prefer labour inputs, as well as being more likely to be negatively affected by severe climate events. In the same vein, households with particularly unstable earnings or risky assets might encourage their children to work in order to diversify risk. ${ }^{7}$ Leaving this unobservable out of the model will induce a spurious relationship between climate shocks experienced and child labour incidence.

To avoid endogeneity issues between climate change and child labour, we create a composite index of the vulnerability to climate change. ${ }^{8}$ More exactly, we construct two indices that take into account the multidimensionality of climate change (Vincent [2004]). The first composite index measures the biophysical vulnerability and is composed of four sub-indicators: (i) the climate volatility, (ii) the climate variability; (iii) the landscape typology and (iv) the soil practicability. These four sub-indicators are constructed via the geo-referenced plot and the household location (GPS data) available in the survey. This biophysical vulnerability (BV) index measure the climate change manifestation for the household, but in an objective way since we consider only climate change consequences on physical variables. The index is neutral and not influenced by social, cultural or resilience factors.

\footnotetext{
${ }^{7}$ Households whose income and assets are most vulnerable to climate damage (e.g. families involved in rainfed cultures production) will benefit more from income diversification generated by child labour than other households. Consequently, they might be more likely to have a child working that can smooth consumption in the event of a severe climate shock. This would also be the case if risk-adverse households are more likely to have working children in order to diversify income sources and are also more likely to invest in self-protection mechanisms that reduce the likelihood of climate damage.

${ }^{8}$ For our study, the use of indicators is the most appropriate method as it enables to describe in a simple manner a complex reality (Vincent [2004]). Indicators reduce also dependence to climatic projections and models (Hahn et al. [2009]).
} 
The second composite index, measuring social resilience, refers to the community's adaptive capacities. Based on information from the community questionnaire, we include in this index: (i) the use of diversification strategies, (ii) the financial capacities, and (iii) the communities services. We use community level information in order to reduce the bias due to omitted variables. ${ }^{9}$ Table A1 (in Annexe) presents in greater details the different sub-indicators selected. We aggregate the categorical indicators using the multiple correspondence analysis (MCA) with a Burt method. Weights used are specified in Table A1.

Finally, the climate change vulnerability index (VC) for a community is expressed as the ratio between the biophysical vulnerability index (BV) and the social resilience index (SR). In all, our novel climate change vulnerability index is defined at a local level and should not be endogenous with the child labour.

\section{Climate change and child labour in Malawi: some stylized facts}

\subsection{Dataset}

Analysis are based on a recent household survey dataset (Third Integrated Household Survey-IHS3) conducted between 2010 and 2011 by the Malawi National Statistics Office. This large and multi-topic survey (more than 12.000 households have been interviewed) is representative at both national and district levels. The IHS3 survey encompasses economic activities, demographics and other sectorial information of households and covers a wide range of topics dealing with the dynamics of poverty. We complement these data with a set of geospatial variables, by using the geo-referenced plot and household locations in conjunction with various geospatial databases that were available in this survey.

\subsection{Climate disasters in Malawi: a rising trend.}

Malawi was particularly prone to adverse climate hazards during the last decade. Seasonal droughts, intense rainfalls, riverine and flash floods have increased in frequency, intensity, and magnitude (Figure 1). A recent report estimated that from 1979 to 2008, natural disasters

\footnotetext{
${ }^{9}$ The idea is that community level information is not self-reported, and hence is not contaminated with individual errors. The endogeneity problem is thus reduced, even if there might still exist some unobservable characteristics affecting both the community and the child labour status. However, we think that the effects of this unobservable are marginal, as communities are widely heterogeneous (in terms of ethnicity, food security and wealth) and households surveyed in a specific community were selected randomly (16 households surveyed by community, 768 communities).
} 
cause the death of more than 2.500 Malawian people and adversely affected another 21.7 million people (GFDRR [2009]). Floods and droughts negatively impacted the household income and food security, since most of the population lives in rural areas. The majority of Malawians participates in low-productivity and low capital subsistence farming, mainly of rain-fed food crops (maize, rice, sorghum, and cassava), and cash crops (ground nuts, tobacco, and cotton), and thus is particularly dependent on climatic conditions.

Figure 2: Droughts and floods trends between 1970 and 2011 in Malawi

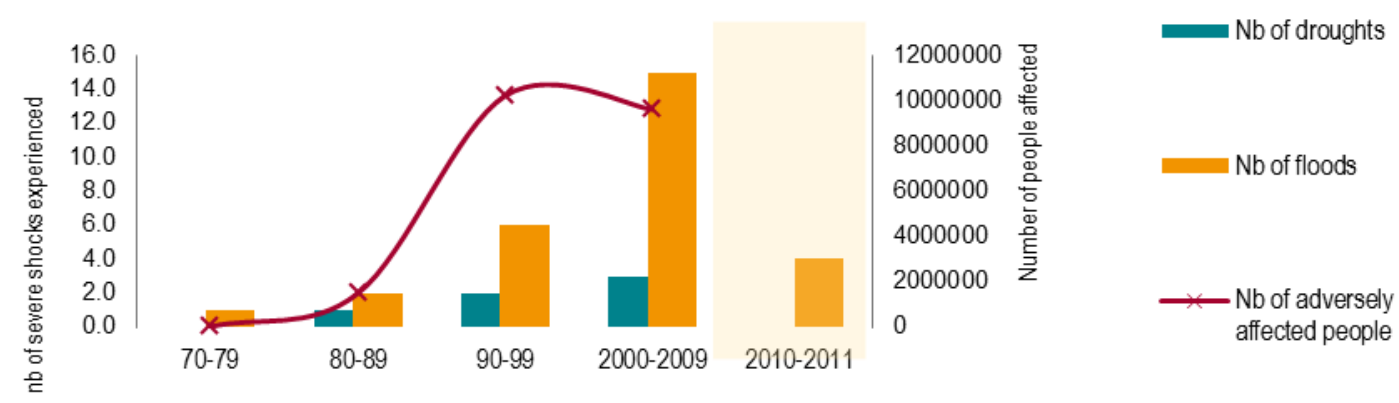

Source: EM-DAT: the OFDA/CRED International Disaster Database, Universite Catholique de Louvain, Bruxelles. www.emdat.be.

\subsection{Children's time allocation.}

Table 1: Children's activities in Malawi (7-14 years old), according to area of residence, gender and climate shock occurrence

\begin{tabular}{lllllll}
\hline & Urban & Rural & Boy & Girl & $\begin{array}{l}\text { No } \\
\text { shock }^{a}\end{array}$ & Shock $^{a}$ \\
\hline \hline $\begin{array}{l}\text { Economic activities } \\
\text { Incidence (\%) }\end{array}$ & 9.35 & 24.51 & 22.87 & 21.37 & 22.13 & 22.1 \\
Intensity (hours) & 9.41 & 10 & 10.37 & 9.53 & 9.22 & 10.87 \\
\hline Domestic tasks & & & & & & \\
Incidence (\%) & 5.86 & 12.6 & 6.01 & 16.9 & 9.5 & 14.01 \\
Intensity (hours) & 9.43 & 11.26 & 10.78 & 11.22 & 10.48 & $\underline{11.63}$
\end{tabular}

(a) Climate shock is a binary variable measuring the droughts and floods experienced by the household during the 2009-2010 reference years.

Source: Third Integrated Household Survey, Malawi, 2010-2011.

Characteristics of child labour are similar to other Sub-Saharan countries. An estimated 
$22 \%$ of children aged 7-14 years, over 700.000 children in absolute terms, were in employment in the 2009-2010 reference years (Table 1). Children work mainly in rural area (24.5\% versus $9.3 \%$ in urban areas) and for their family (more than nine children out of ten work in their family business or farm). We observe little difference in economic activities incidence and intensity according to the gender of the child. Boys in the 7-14 years age group are somewhat more likely to be in employment than girls of the same age $(22.9 \%$ against $21.4 \%)$. Child employment rises with age, but numbers of very young working children are far from negligible. About $8 \%$ of children are in employment by the age of 7 years and $38 \%$ at age 14 years.

One particularity of Malawi is the high school attendance rate. Nearly nine children aged 7-14 years old out of ten were attending school in 2010-2011. This rate is relatively homogeneous throughout the child population, and is independent of the gender or place of residence. This means that almost all child workers in fact cumulate both economic activities and school. Employment is time intensive for Malawian children: they perform an average of 10 weekly hours of economic activities. Employment is not the only category of production concerning children. The same proportion of children is engaged in other productive activities, specifically in household chores (fetching water and collecting firewood). Girls and rural children are more likely to perform household chores than their counterparts, and ignoring this form of work therefore biases estimates of children's work in "favour" of boys or urban children. Table 1 also shows that children participation to household chores is higher when a child belongs to a household that has previously experienced a climate shock. However, little variation by shock occurrence is observed in the economic activities incidence or intensity performed by children.

\section{$5 \quad$ Empirical strategy}

We define $Y_{i j}$ as the probability for a child aged 7 to 14 years old to perform at least one weekly hour in economic activities. This binary dependent variable takes the value of 1 if the child is working, 0 otherwise. We also analyse the impact of climate change on the noneconomic activities, defined as the probability that a child performs domestic tasks (dummy variable). Our sample for this study is restricted to rural children aged from 7 to 14 years old. At the end, we have more than 10000 children in the sample, allocated in 768 communities.

We assume that the conditional probability of a child working follows a Gaussian function, and thus can be estimated by a Probit model, where the parameters $\hat{I}^{2}{ }_{i}$ are estimated by maximum likelihood (Model 1). The probability $Y_{i j}$ for a child i of participating to economic activities $(j=1)$ or of performing domestic tasks $(j=2)$ can be written as follows: 


$$
\left\{\begin{array}{c}
Y_{i j}=1 \text { if } Y_{i j}^{*}>0 \\
Y_{i j}=0 \text { otherwise }
\end{array} \quad(\text { for } j=1,2)\right.
$$

with $Y_{i j}^{*}=\beta_{0}+\beta_{1} V C_{j}+\beta 2 C h_{i}+\beta_{3} C m_{j}+\beta_{4} H H_{j}+\epsilon$

where $V C_{i j}$ represents the vulnerability to climate change index for the household $\mathrm{j}, C h_{i}$, $\mathrm{Cm}_{j}$ and $\mathrm{HH}_{j}$ a set of explanatory variables measuring respectively the child, the household head and the household characteristics. Theses control variables were not arbitrarily selected. We use the most popular control variables identified in the literature for determining child labour for the child characteristics (i.e. age, gender and sibling rank) and for the household head characteristics (i.e. gender, level of education and employment status). The last set of control variables for the household $H H_{j}$ includes financial assets (Log of household income, excluding that from crops, in 1.000 Malawi Kwacha, household rural wealth index and land area), social capital assets (remittances receipt and social network), distance to infrastructures (distance to the nearest para-statal agricultural input provider ADMARC, distance to the nearest road), well-being (food security and Cantril ladder) and household diversification strategies (credit access, crop diversification, social programme access). All the covariates are explained in greater details in Annex A2.

Identical specifications are repeated for estimating the impact of the $\mathrm{VC}$ index on working hours and household chores hours performed by children. Since working and domestic hours are censored at zero for children who do not work or who do not perform domestic tasks, the conventional model used is the Tobit model (Killingsworth, [1983]).

Introducing in a linear manner the $\mathrm{VC}$ index in the child labour regression would bias the coefficient associated to the ratio because it would not take into account the initial value of the BV and SR indices (Kronmal, 1993; Nelder, 1998). We correct the VC ratio by introducing the level of the $\mathrm{VC}$ index in the equation (Model 5), which can be represented by levelVC $_{j}=\left(\left(\text { BVindex }_{i}\right)^{2}+(\text { SRindexi })^{2}\right)^{1 / 2}$.

$$
Y_{i j}^{*}=\beta_{0}+\beta_{1} V C_{i}+\beta 2 \text { levelV } C_{i}+\beta_{3} C h_{i}+\beta_{4} C m_{j}+\beta_{5} H H_{j}+\epsilon
$$

We perform additional regression aiming at differentiating the specific impacts of the subindicators, for a deeper understanding of the links between climate change and child labour. Model 3 replaces in the first equation the VC index by the BV and the SR indices:

$$
Y_{i j}^{*}=\beta_{0}+\beta_{1} B V_{j}+\beta 2 S R_{j}+\beta_{3} C h_{i}+\beta_{4} C m_{j}+\beta_{5} H H_{j}+\epsilon
$$




\section{Results and discussion}

Table 2 presents the key marginal effects from Probit/Tobit regressions with the VC index as variable of interest. We can see that the vulnerability to climate change has a significant and negative influence on the probability to be employed and on working hours. For each one unit increase of the VCC index, the probability for a child to participate in economic activities decreases by 0.128 units, while working time decrease by almost 6 weekly hours. The incidence and intensity of household chores performed by children seems to be unrelated to the vulnerability to climate change.

Table 2: Regressions of the probability of working (economic activities or household chores) for rural children aged 7 to 14 years old (marginal effects)

\begin{tabular}{lllll}
\hline & Economic activities & \multicolumn{3}{l}{ Domestic tasks } \\
\hline VC Index & Incidence (a) & Intensity (b) & Incidence (a) & Intensity (b) \\
\hline \hline Coefficient & $-0.128^{* * *}$ & $-5.736^{* * *}$ & 0.004 & 0.722 \\
& -0.035 & -1.501 & -0.025 & -2.016 \\
\hline Level & $-0.125^{* * *}$ & $-8.239^{* * *}$ & $-0.033^{*}$ & -2.93 \\
& -0.024 & -1.266 & -0.018 & -1.788 \\
\hline BV Index & $-0.178^{* * *}$ & $-9.675^{* * *}$ & 0.019 & -1.772 \\
& -0.03 & -1.317 & -0.021 & -1.82 \\
SR Index & 0.017 & -1.206 & 0.00 & -2.782 \\
& -0.029 & -1.332 & -0.022 & -1.893 \\
\hline
\end{tabular}

*** p $0.01, * * \mathrm{p} \quad 0.05, * \mathrm{p} \quad 0.1$ Robust standard errors in parentheses.

(a) Probit regressions. Only marginal effects are reported. (b) Tobit regressions. Only marginal effects are reported. Source: Third Integrated Household Survey, Malawi, 2010-2011.

Results are still consistent when taking the level of vulnerability into account, indicating that the probability for a child of performing economic activities decreases by 0.125 when both the BV and SR index increases by one unit. Expressed in terms of standard deviation (s.d.), one s.d. increase in climate change vulnerability decreases child economic activities incidence (resp. intensity) by 0.079 (resp. 0.082) s.d. Again, the probability of performing domestic tasks is not affected by the level of the $\mathrm{VC}$ ratio.

Taking into account the specific impact of each indicator brings a new perspective on the climate change-child labour nexus. Basically, only the biophysical vulnerability has a significant and high impact on child employment, while the communities' resilience seems not influence. 
The main explanation of this negative relationship is that the increase in frequency of climate disasters may also lead to a reduction in the total volume of economic activities, especially in rural areas. In a country where rain-fed agriculture is dominant, repeated extreme floods and droughts can destroy fields and farm unit, and consequently reduce the rural labour demand. In this context, child labour should decrease, as children participation to work is an adjustment variable in the labour market. Child labour is thus seen as an adjustment variable to the household labour market demand, due to moral hazard concerns and market imperfections (Boutin [2012b]; Dumas [2013]).

Obviously these findings have implications in terms of policy. Incentives aiming at increasing resilient strategies (as for example expanding social safety net programme) could have a beneficial effect on child labour only if they are combined with policies aiming at improving markets functioning (development of infrastructure, reduction in transaction costs, etc.) in order to reduce the farmer reliance on their own child workforce. On the contrary, stimulating the familial labour demand (through for example micro-credit schemes) could have adverse effects on child labour.

\section{Conclusion}

In this paper, we test the hypothesis that climate change increase farmers' reliance on child labour. Using our all-inclusive work definition (economic activities and domestic tasks), we find a significant and negative relationship between the vulnerability to climate change and child labour incidence and intensity. A higher vulnerability to climate change leads to a reduction in the use of child labour. This is consistent with the view that children are an adjustment variable to fluctuations in local labour market, due to imperfect markets and moral hazard. The present paper is meant to be a contribution towards a deeper understanding of why child labour still remains while school attendance rate is high.

\section{References}

ADGER W. N. [1999], "Social vulnerability to climate change and extremes in coastal Vietnam", World Development 27, 249-269.

BASU K. and VAN P. H. [1998], "The economics of child labour", The American Economic Review, 88(3), p. 450-477.

BEEGLE K., DEHEJIA R. H. and GATTI R. [2003], "Child Labour, Crop Shocks, and Credit Constraints", NBER Working Paper No. W10088, Cambridge: National Bureau of 
Economic Research.

BIRKMANN J. [2006], "Measuring Vulnerability to Promote Disaster resilient Societies: Conceptual Frameworks and definitions", in "Measuring Vulnerability to Natural Hazards - Towards Disaster Resilient Societies", edited by Birkmann, J., United Nations University Press, Tokyo, 9-54.

BOHARA A. and VASQUEZ W. [2010], "Household shocks, child labor, and child schooling : evidence from Guatemala", Latin American Research Review 45, no. 3 (2010): 165-186.

BOUTIN D. [2012b], "Essai sur la pauvrete, la vulnerabilite et le travail des enfants", $\mathrm{PhD}$ dissertation, University of Bordeaux.

BOUTIN D. [2012b], "Family farming, child labour and the wealth paradox: evidence from Mali", Economics Bulletin, Vol. 32 No. 4, p. 3471-3479.

DUMAS C. [2013], "Market Imperfections and Child Labor", World Development, Elsevier, Vol. 42[C], pages 127-142.

FUSSEL H. M. [2007], "Vulnerability: a generally applicable conceptual framework for climate change research", Global Environmental Change, 17:155-167.

GFDRR [2009], "Economic Vulnerability and Disaster Risk Assessment in Malawi and Mozambique: Measuring Economic Risks of Droughts and Floods".

GUARCELLO L., MEALLI F. and ROSATI F. C. [2010], "Household vulnerability and child labor: the effect of shocks, credit rationing, and insurance", Journal of Population Economics, Springer, Vol. 23[1], pages 169-198, January.

GUARCELLO L., LYON S. and ROSATI F. C. [2006], "The Twin Challenges of Child labour and Youth Employment in Ethiopia”, UCW Working Paper 18, Understanding.

GROOTAERT C. and KANBUR R. [1995], "Child Labor: A Review", Washington, Policy Research Working Paper 1454, The World Bank.

GUILLAUMONT P. and SIMONET C. [2011], "Designing an Index of Structural Vulnerability to Climate Change", Ferdi Policy Brief / 18.

KILLINGSWORTH M. R. [1983], "Union-Nonunion Wage Gaps and Wage Gains: New Estimates from an Industry Cross-Section", The Review of Economics and Statistics, MIT 
Press, Vol. 65[2], pages 332-336, May.

KONDYLIS F. and MANACORDA M. [2012], "School Proximity and Child Labor: Evidence from Rural Tanzania", Journal of Human Resources, University of Wisconsin Press, Vol. 47[1], pages 32-63.

KRONMAL R. A. [1993], Spurious Correlation and the Fallacy of the Ratio Standard Revisited, Journal of the Royal Statistical Society, Series A [Statistics in Society], 156 [3], p. 379-392.

NELDER J. A. [1998], "The selection of terms in response surface models? How strong is the weak heredity principle?", The American Statistician, 52: 3158.

PARIKH A. and SADOULET E. [2005], "The effect of parentsâ occupation on child labor and school attendance in Brazil", Department of Agricultural and Resource Economics working paper 1000. California: University of California Berkeley.

UCW (Understanding Children Work) [2011], "Migrations, changements climatiques, travail des enfants et emploi des jeunes", UCW Working Paper, Septembre 2011.

UNICEF [2008], "Climate change and children, a human security challenge", Innocenti Research Center, Policy Review Paper, Florence.

VINCENT K. [2004], "Creating an index of social vulnerability to climate change for Africa", Technical Report 56. Norwich, U.K.: Tyndall Centre for Climate Change Research, University of East Anglia. 


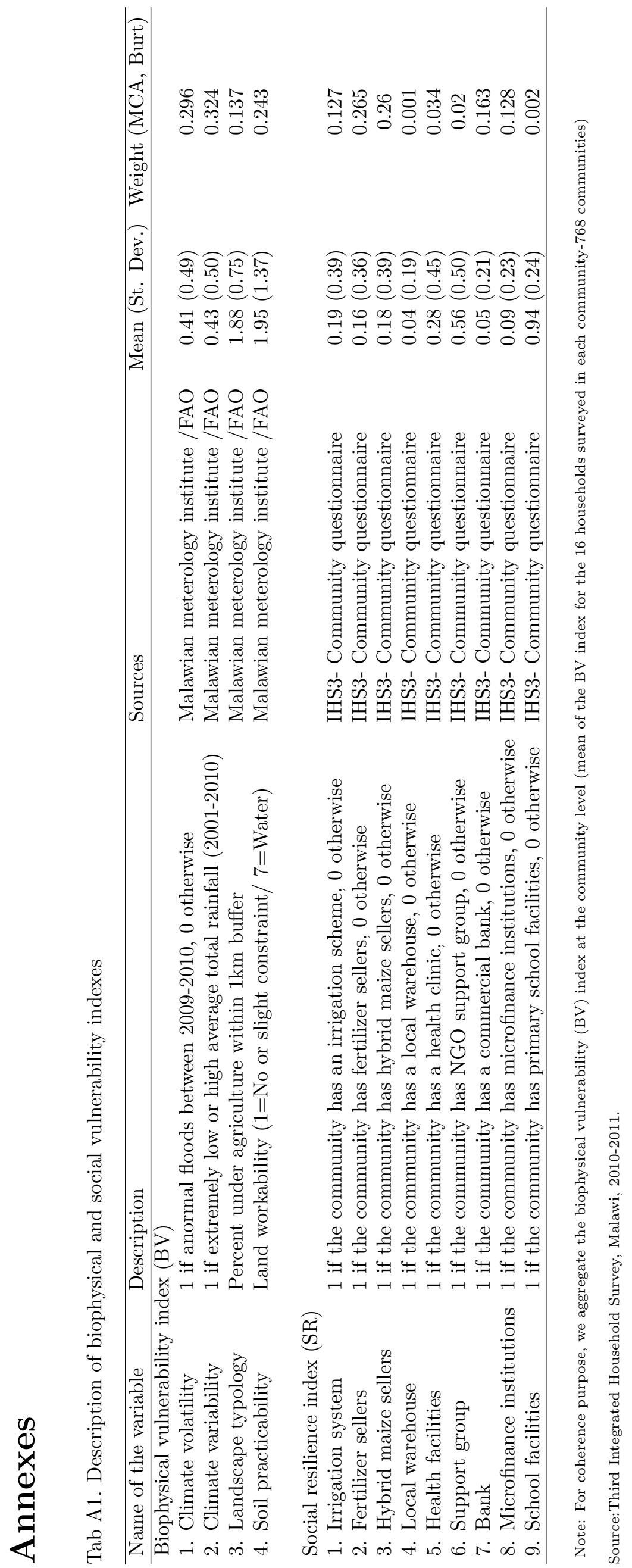




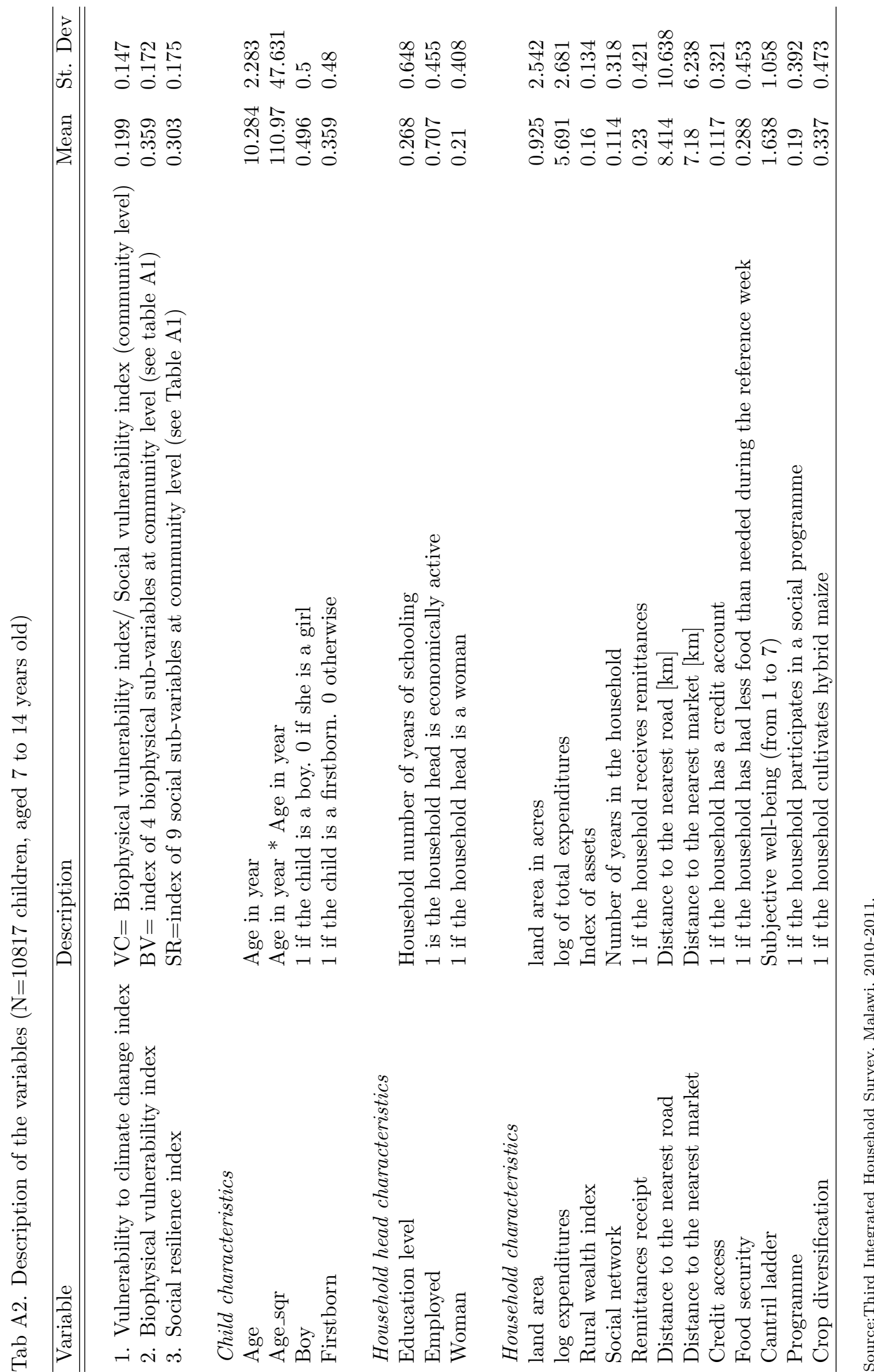

